\title{
Impact of dental plaque control on the survival of ventilated patients severely affected by COVID-19 infection: An overview
}

\author{
Fouad Hussain Al-Bayaty ${ }^{1, A, B, D, E}$, Najwa Baharudin ${ }^{1, B, D, E}$, Mohamed Ibrahim Abu Hassan ${ }^{2, E}$ \\ ${ }^{1}$ Center of Periodontology Studies, Faculty of Dentistry, Universiti Teknologi MARA, Sungai Buloh, Malaysia \\ ${ }^{2}$ Center of Restorative Dentistry Studies, Faculty of Dentistry, Universiti Teknologi MARA, Sungai Buloh, Malaysia \\ A - research concept and design; $\mathrm{B}$ - collection and/or assembly of data; $\mathrm{C}$ - data analysis and interpretation; \\ $D$ - writing the article; $E$ - critical revision of the article; $F$ - final approval of the article
}

Address for correspondence

Fouad Hussain Al-Bayaty

E-mail: fouad@uitm.edu.my

Funding sources

None declared

Conflict of interest

None declared

Received on November 20, 2020

Reviewed on January 31,2021

Accepted on February 1, 2021

Published online on September 30, 2021

Cite as

Al-Bayaty FH, Baharudin N, Abu Hassan MI. Impact of dental plaque control on the survival of ventilated patients severely affected by COVID-19 infection: An overview. Dent Med Probl. 2021;58(3):385-395. doi:10.17219/dmp/132979

DOI

$10.17219 / \mathrm{dmp} / 132979$

Copyright

○ 2021 by Wroclaw Medical University

This is an article distributed under the terms of the

Creative Commons Attribution 3.0 Unported License (CC BY 3.0)

(https://creativecommons.org/licenses/by/3.0/).

\begin{abstract}
This overview was conducted to highlight the importance of adequate oral hygiene for patients severely affected by coronavirus disease 2019 (COVID-19) due to infection with severe acute respiratory syndrome coronavirus 2 (SARS-CoV-2). These are patients who were admitted to the intensive care unit (ICU) to receive oxygen through mechanical ventilation due to severe pneumonia as a complication of COVID-19. Various dental plaque removal methods for ventilated patients were discussed with regard to their efficacy. The use of chemical agents was also considered to determine which one might be proposed as the best choice. Also, oral care programs or systems that can be implemented by ICU nurses or staff in the case of these ventilated patients were suggested based on evidence from the literature. These interventions aim to reduce microbial load in dental plaque/biofilm in the oropharynx as well as the aspiration of the contaminated saliva in order to prevent the transmission of the dental plaque bacteria to the lungs or other distant organs, and reduce the mortality rate.
\end{abstract}

Keywords: COVID-19, mechanical ventilation, ventilator-associated pneumonia, oral hygiene care, cytokine storm 


\section{Introduction}

The development of non-oral diseases may be promoted directly or indirectly by periodontal pathogens. Gram-negative anaerobic bacteria, which can be found in abundance in the oral cavity, release endotoxins that may directly contribute to the development of systemic diseases. This association was described by Socransky et al. as early as in $1998 .{ }^{1}$ These oral pathogenic bacteria may reach other organs, such as the lungs, by direct inoculation or travel to distant organs via the bloodstream or the lymphatic system. Bacterial accumulation on the teeth due to inadequate oral hygiene, with or without other environmental factors, may induce not only the host inflammatory response, with the possible consequences of bone loss and subsequent periodontitis, ${ }^{2}$ but also become systemically detrimental to the individual.

Coronavirus disease 2019 (COVID-19) was first discovered in Wuhan, China, at the end of 2019. Unfortunately, COVID-19 spread rapidly on a global scale and led to a full-blown pandemic that was announced by the World Health Organization (WHO) and the Public Health Emergency of International Concern (PHEIC) in March 2020. The first confirmed death associated with COVID-19 was in Wuhan on January $9,2020^{3}$ and the first death outside of mainland China was reported in February in the Philippines. ${ }^{4}$ The first casualty outside of Asia occurred in France and was recorded on February 14, 2020. ${ }^{3}$ By the end of February, many more deaths related to COVID-19 had been recorded in countries outside of mainland China, including Iran, South Korea and Italy. By March 2020, when the disease was declared a pandemic, many more countries had reported deaths caused by COVID-19. ${ }^{5}$ As of September 30, 2020, according to WHO, the death toll due to COVID-19 had reached $1,004,421 .^{6}$

\section{Methodology}

The relevant literature was selected from 3 databases, including Web of Science, PubMed and Google Scholar searches. To ensure all relevant studies were included in the search outcome, keywords were carefully selected, and each keyword was searched both separately and together with the keyword "COVID-19". Other keywords used were as follows: "cytokine storm"; "plaque control"; "oral care"; "oral hygiene care (OHC)"; "mechanical ventilation"; "intensive care unit (ICU)"; and "ventilator-associated pneumonia (VAP)". Only articles in English were considered. The articles were chosen based on their association with the title of this literature review in terms of their title, relevant abstract and full-text, as long as they were related to the topic and aim of this overview

\section{Cytokine storm and COVID-19}

The leading cause of death for patients affected by COVID-19 is respiratory failure, which is consistent with the typical cause of death related to other viruses. This was determined by Chen et al. and reported in their article describing the epidemiological and clinical characteristics of 99 cases of COVID-19 pneumonia in Wuhan, China. ${ }^{7}$ Their descriptions coincide with those of Wang et al. ${ }^{8}$ In order to improve the survival rate of severely affected patients, invasive mechanical ventilation has been recommended. This was suggested by Xie et al. as part of COVID-19 management in China. ${ }^{9}$ Such patients undergo mechanical ventilation until their lungs recover from the injury. Mortality from COVID-19 can be due to other reasons, including septic shock and multi-organ failure. Xie et al. reported that as of February 10, 2020, about 15\% of patients in Wuhan developed severe pneumonia and $6 \%$ required ventilatory support. ${ }^{9}$ Of those who died before January 30, 2020, approx. $25 \%$ received extracorporeal membrane oxygenation (ECMO). ${ }^{9}$ The role of secondary bacterial infection in reducing patients' survival has been mentioned in the literature, including articles by Huang et al. ${ }^{10}$ and Liu et al., ${ }^{11}$ but the mechanism has not been described clearly. COVID-19 is associated with other complications that may lead to death, including cardiac shock caused by acute myocardial injury, myocarditis and acute kidney injury. ${ }^{8,10}$ Table 1 summarizes the literature on the reported COVID-19 cases.

According to a review by Ragab et al., the innate immune response involves the activity of various inflammatory cytokines and chemokines. ${ }^{12}$ Three of the most important cytokines are interleukin (IL)-1, IL-6 and tumor necrosis factor-alpha (TNF- $\alpha$ ). They are mainly produced and released by tissue macrophages, mast cells, endothelial cells, and epithelial cells. The term "cytokine storm" is used to describe a sudden acute increase in circulating proinflammatory cytokines, including IL-1, IL-6 and TNF- $\alpha$, and interferon (IFN) due to the migration of immune cells, such as macrophages, neutrophils and $\mathrm{T}$ cells, from the circulation to the site of infection. The sudden increase ultimately results in the destruction of host tissues, brought about by the disruption of the endothelial cell-cell interaction, vascular barrier and capillary damage, and diffuse alveolar injury.

Clinically, a cytokine storm is a life-threatening situation in which the patient requires intensive care due to a high risk of death. Patients experiencing a cytokine storm typically exhibit symptoms of significant systemic inflammation, such as intense fever and hyperferritinemia, hemodynamic instability, and eventually multi-organ failure that can lead to death if not addressed urgently. These symptoms are believed to be the effect of increased levels of circulating proinflammatory cytokines, such as IL-1, IL-6, IL-18, interferon-gamma (IFN- $\gamma$ ), and TNF- $\alpha$. Acute lung injury is one of the possible consequences, and it may even advance into acute respiratory distress syndrome (ARDS). ${ }^{13}$ 
Table 1. Literature on the reported coronavirus disease 2019 (COVID-19) cases

\begin{tabular}{|c|c|c|}
\hline Articles & Type of literature & Relevant main findings \\
\hline Ruan et al. ${ }^{4}$ & $\begin{array}{l}\text { letter to the editor } \\
\text { on a retrospective } \\
\text { multi-center study }\end{array}$ & $\begin{array}{l}\text { - The predictors of a fatal outcome in COVID-19 patients included age, the presence of underlying diseases, the } \\
\text { presence of secondary infection, and elevated inflammatory indicators in the blood. } \\
\text { - The results obtained from this study also suggest that mortality for COVID-19 might be due to virus-activated } \\
\text { "cytokine storm syndrome" or fulminant myocarditis. }\end{array}$ \\
\hline Chen et al. ${ }^{7}$ & $\begin{array}{l}\text { retrospective } \\
\text { single-center } \\
\text { study }\end{array}$ & $\begin{array}{l}\text { - The 2019-nCoV infection had a clustering onset, was more likely to affect older men with comorbidities and could } \\
\text { result in severe, or even fatal respiratory diseases, such as ARDS. } \\
\text { - The early identification and timely treatment of critical cases of 2019-nCoV infection are important. } \\
\text { - Effective life support and the active treatment of complications should be provided to effectively reduce the severity } \\
\text { of patients' condition. }\end{array}$ \\
\hline Wang et al. ${ }^{8}$ & $\begin{array}{l}\text { retrospective } \\
\text { single-center } \\
\text { study }\end{array}$ & 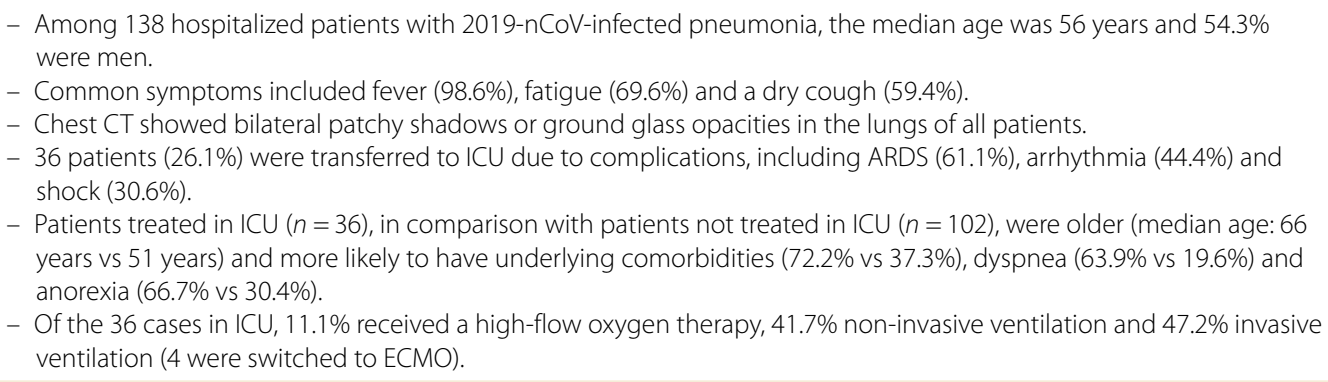 \\
\hline Huang et al. ${ }^{10}$ & $\begin{array}{l}\text { retrospective } \\
\text { single-center } \\
\text { study }\end{array}$ & $\begin{array}{l}\text { - By January 2, 2020, } 41 \text { admitted hospital patients had been identified as having laboratory-confirmed } 2019-n C o V \\
\text { infection. } \\
\text { - Most of the infected patients were men (73\%), and less than half had underlying diseases (32\%), including diabetes } \\
\text { ( } 20 \%) \text {, hypertension (15\%) and CVD (15\%); the median age was } 49.0 \text { years (IQR: } 41.0-58.0) \text {. } \\
\text { - Common symptoms at the onset of the illness were fever (98\%), cough (76\%), and myalgia or fatigue (44\%); less } \\
\text { common symptoms were the production of sputum (28\%), a headache (8\%), hemoptysis (5\%), and diarrhea (3\%); } \\
\text { dyspnea developed in 55\% of patients, 63\% of patients had lymphopenia and all } 41 \text { patients had pneumonia with } \\
\text { abnormal findings on chest CT. } \\
\text { - Complications ARDS (29\%), RNAaemia (15\%), acute cardiac injury (12\%), and secondary infection (10\%). } \\
\text { - In comparison with non-ICU patients, ICU patients had higher plasma levels of IL-2, IL-7, IL-10, GSCF, IP-10, MCP-1, } \\
\text { MIP-1a, and TNF-a. }\end{array}$ \\
\hline Liu et al. ${ }^{11}$ & $\begin{array}{l}\text { retrospective } \\
\text { multi-center study }\end{array}$ & $\begin{array}{l}\text { - The majority of patients with 2019-nCoV pneumonia presented with fever as the first symptom, and most showed } \\
\text { the typical manifestations of viral pneumonia on chest imaging. } \\
\text { - Middle-aged and elderly patients with underlying comorbidities are susceptible to respiratory failure and may have } \\
\text { poorer prognoses. }\end{array}$ \\
\hline
\end{tabular}

2019-nCoV - 2019 novel coronavirus; ARDS - acute respiratory distress syndrome; CT - computed tomography; ICU - intensive care unit; ECMO - extracorporeal membrane oxygenation; CVD - cardiovascular diseases; IQR - interquartile range; IL - interleukin; GSCF - granulocyte colony-stimulating factor; IP-10 - interferon gamma-induced protein-10; MCP-1 - monocyte chemoattractant protein-1; MIP-1a - macrophage inflammatory protein-1 alpha; TNF-a - tumor necrosis factor-alpha.

According to a review article by Coperchini et al., ARDS can be defined as the presence of bilateral lung infiltrates accompanied by severe hypoxemia. ${ }^{14}$ A cytokine storm can not only result in ARDS, but also in a range of clinical circumstances, such as pneumonia, sepsis, pancreatitis, and the need for a blood transfusion. It has been suggested that the pathogenesis of ARDS involves inflammatory injury to the alveolocapillary membrane,which leads to increased lung permeability and the exudation of proteinrich pulmonary edema fluid into the airspaces, which results in respiratory insufficiency. ${ }^{15}$

One of the main causes of morbidity and mortality for COVID-19 patients is the development of ARDS, which consequently leads to low oxygen saturation. The exact mechanism of ARDS in COVID-19 patients is still not fully understood, but reports by Chen et al., ${ }^{7}$ Huang et al. ${ }^{10}$ and Lai et al. ${ }^{16}$ suggest that the excessive synthesis and release of proinflammatory cytokines may be one of the key contributing factors. There is further support for this hypothesis, as it has been found that circulating levels of white blood cells, neutrophils, procalci- tonin, C-reactive protein (CRP), and other inflammatory indices were significantly higher in COVID-19 patients in ICU as compared to non-ICU patients. ${ }^{8,17}$ Another review by Tang et al. proposes that severe acute respiratory syndrome coronavirus 2 (SARS-CoV-2) infection activates the innate and adaptive immune responses, ${ }^{18}$ which leads to uncontrolled inflammatory responses, and ultimately to a cytokine storm. ${ }^{19}$ The review also suggests that SARS-CoV-2 infection not only causes an inflammatory cytokine storm, but that a cytokine storm may lead to ARDS or extrapulmonary multi-organ failure, ${ }^{20}$ which can result in the exacerbation of COVID-19, or even death. ${ }^{18}$ Table 2 summarizes the literature on the cytokine storm related to COVID-19 cases.

Chen et al., ${ }^{7}$ Wang et al., ${ }^{8}$ Huang et al., ${ }^{10}$ and Liu et al. ${ }^{11}$ all reported similar major symptoms of COVID-19 at the initial onset of the disease. These major symptoms include fever, coughing, myalgia/muscle ache, and fatigue. These articles also listed some of the less common symptoms, which include headache, diarrhea, chest pain, nausea, and vomiting. The majority of patients 
Table 2. Literature on the cytokine storm related to COVID-19 cases

\begin{tabular}{|l|l|l|l}
\hline Articles & Type of literature & Relevant main findings \\
\hline Ragab et al. ${ }^{12}$ & - & COVID-19 is transmitted via droplets or direct contact, and infects the respiratory tract, resulting in pneumonia \\
& in most cases and ARDS in about 15\% of cases.
\end{tabular}

Th17 - T-helper 17 cells; SARS-CoV-2 - severe acute respiratory syndrome coronavirus 2.

(in the case of 1 center, all reported patients ${ }^{10}$ ) developed pneumonia with the evidence of bilateral lung lesions based on various imaging investigations. Acute respiratory distress syndrome was described as one of the complications of COVID-19, with some patients reported to deteriorate quite rapidly. This pattern of deterioration makes it necessary to transfer patients to ICU, where they can receive non-invasive or invasive ventilation as well as ECMO. Patients in the older age range (median $(M e)$ : 49-57 years) with complications due to underlying systemic conditions, such as hypertension, cardiovascular diseases (CVD) and diabetes, have poorer prognoses. This is consistent with the findings of Yang et al., who documented cases of COVID-19 in China. ${ }^{21}$

\section{Mechanical ventilation and poor oral health}

For patients receiving mechanical ventilation, poor oral health is a common issue. This concern was highlighted by Adib-Hajbaghery et al. in an article published in 2013. ${ }^{22}$ Poor oral health can be a significant concern, as these patients often develop oral health problems in a short period of time due to numerous causes, including malnutrition, the placement of the tracheal tube and the nasogastric tube in the oral cavity, a reduced fluid intake, reduced salivation caused by prolonged mouth opening, and polypharmacy. These reasons were discussed by Kaya et al. ${ }^{23}$ Atypical pneumonia has been reported in some cases of COVID-19 and, as suggested by Huang et al., it may be associated with secondary bacterial infection. ${ }^{10}$ For this reason, special attention should be given to oral health and periodontal-related diseases in particular, as the latter are commonly associated with Gram-negative pathogenic bacteria, which can potentially complicate the condition of COVID-19 patients.
Due to its distinctive low oxygen tension and $\mathrm{pH}$, which tends to skew toward an acidic environment, as well as the abundance of nutrients in the mouth, the oral cavity is regarded as an ideal microbial incubator. According to Fields, either naturally occurring (e.g., enamel and cementum) or artificially introduced (e.g., dental restorations, fixed or removable prostheses, and implants) hard surfaces in the mouth favor the formation of microbial sediments, which results in the establishment of dental biofilm. ${ }^{24}$ For reasons mentioned earlier, namely a reduced fluid intake and reduced salivation, dental biofilm is more likely to form and evolve in ICU patients as compared to other patients. This finding was reported in a study by Panchabhai et al. as early as in $2009 .{ }^{25}$

In a study by Pedreira et al. on children receiving mechanical ventilation over a period of $48 \mathrm{~h}$, Gram-negative bacteria were found to be the prevalent pathogens in their oropharyngeal secretions. ${ }^{26}$ Since dental biofilm mass increases over time, combined with the accretion of aerobic and anaerobic bacteria and subsequent colonization by predominantly anaerobic Gram-negative bacteria, the presence of dental biofilm may be an essential factor in determining the composition of oral and pharyngeal environment. This was highlighted in a literature review authored by Hillier et al. ${ }^{27}$ Furthermore, other studies, including that by Rello et al., ${ }^{28}$ suggested that biofilm within the oral cavity could be populated by respiratory pathogens, and that the microbes associated with nosocomial pneumonia were found to originate from the oral cavity. Therefore, the presence of poor oral conditions can potentially endanger patients admitted to ICU, especially those undergoing mechanical ventilation.

Studies by Scannapieco et al. ${ }^{29}$ and Panchabhai et al. ${ }^{25}$ suggested that some of the bacteria in dental plaque, including Staphylococcus aureus and Pseudomonas aeruginosa, can be major causes of VAP. In fact, Adib-Hajbaghery et al. ${ }^{22}$ and Haghighi et al. ${ }^{30}$ examined the impact of oral care interventions on the incidence of VAP among ICU patients undergoing mechanical ventilation and showed positive outcomes for patients that received an intervention. 
One of the most common inflammatory diseases in adults is periodontal disease. A study published in 2017, concerning the global burden of the disease, found that severe periodontal disease was the $11^{\text {th }}$ most prevalent condition in the world, making it a significant public health issue. ${ }^{31}$ The burden on healthcare systems is expected to increase as the global population ages, and this may become a significant concern. With advances in periodontal research, there is considerable evidence, such as that presented by Kim and Amar, ${ }^{32}$ that links periodontal disease with various extraoral and systemic diseases, including type 2 diabetes mellitus, CVD, respiratory tract infections, adverse pregnancy outcomes, and neurodegenerative diseases.

Great interest has been shown in the connection between oral condition, inflammation and systemic diseases, as manifested by many recent studies that have explored these subjects. Microorganisms in the oral cavity not only cause local intraoral inflammation, but also directly contribute to systemic inflammation. A rise in inflammation is the result of toxins being released by microorganisms and the leakage of microbial by-products into the bloodstream. It is vital to acquire more knowledge about the connection between oral and systemic inflammation to better understand the detrimental effects of intraoral inflammation on other organ systems as well as the possibility of increasing the risk of developing non-oral diseases due to oral diseases. This interrelationship and its impact were discussed in a review article by Kim and Amar as early as in $2006 .^{32}$

\section{Dental plaque/biofilm as a risk factor for COVID-19 ventilated patients}

Paster et al. conducted pioneering research to determine the microbial population in the mouth and found that there are approx. 500-700 prevalent taxa. ${ }^{33}$ Oral microbiota, microflora, and microbiome are some of the terms used to describe the intraoral microbial community. These microorganisms have previously been isolated from the saliva, gingival epithelium and other surfaces of the oral mucosa, with the highest density found in dental plaque. As the technology for bacterial detection and profiling improve, more studies are carried out to determine the microbiome of various oral niches, including the various sites of mucous membranes and the tongue, as well as within dental plaque itself. Liu et al. explored the oral microbiome using the most current technique at the time of their study. ${ }^{34}$ Oral diseases, such as periodontitis and dental caries, are known to be strongly associated with particular bacterial species that are commonly found in the microbial diversity of the dental biofilm. These groups of bacteria, collectively characterized as pathogenic, have progressively been correlated with systemic infections.
There has been interest in exploring the content of the dental biofilm of patients with known systemic symptoms or diseases, as it may provide more information about the connection between the disease of interest and oral microorganisms. This was discussed by Kim and Amar in $2006 .{ }^{32}$ In a review paper, Gomes-Filho et al. examined the studies which demonstrated that an unhealthy oral cavity was a predisposing factor for respiratory infections, and suggested that oral or non-oral pathogens present in the oral cavity could contribute to respiratory disease. ${ }^{35}$

As early as in 1997, Garrouste-Orgeas et al. suggested that the colonization of the oropharynx with bacteria is a critical factor in the development of nosocomial pneumonia. ${ }^{36}$ Munro and Grap discussed this possible mechanism and suggested that the microbes associated with the incidence of VAP might flourish from the center of infection, containing the established habitat for other pathogenic bacteria. ${ }^{37}$ This is thought to be possible, since the dental biofilm creates a favorable environment for VAPcausing bacteria, which can attach to either tooth surfaces or other microbes present in the biofilm. This enables them to be transmitted from the oral cavity to the lungs, which may lead to the development of VAP. This hypothesis was introduced as far back as in 1992 by Scannapieco et al., ${ }^{29}$ and discussed further by Garrouste-Orgeas et al..$^{36}$ and El-Solh et al. ${ }^{38}$

Researchers in the past suggested that there was a correlation between periodontal disease, particularly periodontitis, and systemic diseases, including lung diseases or infections. The mechanism for the relation between periodontal disease and respiratory illnesses is still not clear, with the former not always leading to or increasing the incidence of the latter. However, the presence of periodontal disease is thought to change the typical behavior of respiratory illnesses, possibly due to changes in the content and dynamics of oral microorganisms, brought about by the presence of periodontal infection. Weidlich et al. discussed this possible mechanism in their review article published in $2008 .{ }^{39}$ The microaspiration of oral microorganisms in patients with periodontal infection may have different outcomes when compared to patients without periodontal infection, possibly due to differences in the microbial composition.

Patients severely affected by COVID-19 require mechanical ventilation to increase their chances for survival. The endotracheal tube (ETT) acts as the interconnection between the patient's lungs and the ventilator. The insertion of the tube via intubation is followed by changes in the oral micro-environment and subsequently alters the composition of the oral microbiome. Various studies in the past, including those by Scannapieco et al. ${ }^{29}$ and Berry et al., ${ }^{40}$ suggested that changes in the oral environment facilitated the establishment and propagation of respiratory pathogens and other possible opportunistic pathogens that may be present in the oral cavity or inside the pulmonary system itself. How the shift in the content 
of the microbiota came about is still not entirely clear. However, it has been suggested that it may be due to the placement of ETT inside the oral cavity and through the trachea, which hinders the removal of dental biofilm, reduces the saliva flow and dries the mucosa due to persistent mouth opening. When managing medical conditions (i.e., treating the condition being the main reason for hospitalization), any medical interventions or even medications given may also contribute to microbial changes.

\section{Retentive factors for dental biofilm}

The presence of pathologic changes in periodontal anatomy, such as increased pocket depth, intrabony pockets and furcation involvements, becomes a local contributing factor in the oral cavity that allows dental biofilm to accumulate. Calculus may be present supragingivally, which may encourage the development of the inflammation of the marginal gingiva, or subgingivally, which creates irregular porous surfaces that can act as reservoirs for periodontal pathogens and endotoxins. In a review article, Genco and Borgnakke stated that the presence of subgingival calculus and its plaque layer were associated with the development of periodontitis, with higher rates of disease progression in adolescents and adults. ${ }^{41}$

There are other local contributing factors, including poorly completed or deteriorating restorations (i.a., those with overhangs), rough surfaces, subgingival margins, marginal discrepancies, and under- or over-contoured crowns. Fixed appliances like orthodontic braces, crowns and bridges as well as pathological changes, such as endodontic infections, root fractures and cervical root resorption, are all considered facilitating factors that contribute to the accumulation of dental plaque/biofilm. The elimination of most or all (if possible) of these local factors aims to reduce the bacterial load in the oral cavity, which would specifically aid COVID-19 patients by reducing the likelihood of complications like atypical pneumonia.

\section{Oral hygiene for COVID-19 patients undergoing mechanical ventilation in ICU}

It has been established that poor oral health may contribute to or complicate some systemic diseases, including respiratory ones. Coker et al. discussed this concept with dependent older adults as a focus of interest. ${ }^{42}$ Various studies, as highlighted by Yurdanur and Yagmur in their review, ${ }^{43}$ have associated VAP with poor plaque control. The aspiration of oropharyngeal secretions, with their content being influenced by the composition of the dental biofilm, is an independent risk factor for VAP and, according to a systematic review by Berry et al., ${ }^{44}$ is a key causative factor for nosocomial infection in ICU patients. A review conducted by Cirillo et al. found that VAP was a complication in $8-28 \%$ of patients receiving mechanical ventilation. ${ }^{45}$ Furthermore, original research by Inchai et al. found that a 30-day mortality rate in patients with VAP caused by drug-resistant Acinetobacter baumannii was $21.2 \%$, while the rates for multi-drug-resistant, extensively drugresistant, and pan-drug-resistant Acinetobacter baumannii VAP were $31.9 \%, 56.8 \%$ and $66.7 \%$, respectively. ${ }^{46}$

The same systematic review by Berry et al. showed that bacteria accountable for VAP, which may include Acinetobacter baumannii, colonize the oral mucosa and are collected in the dental biofilm of intubated patients. ${ }^{44}$ Therefore, providing adequate oral care should be a priority for critically ill patients in ICU, as it is essential in reducing the incidence of VAP. Adequate oral care may not only affect the clinical outcome of these patients, but also improve their overall wellness. This is apparent in the findings of a study by DeKeyser Ganz et al., ${ }^{47}$ and again highlighted in a review article by Atay and Karabacak. ${ }^{48}$

According to Feider et al., when providing adequate oral care to orally intubated and critically ill patients, the primary goal should be to improve oral hygiene. ${ }^{49}$ This should result in a reduction in the bacterial population in the oropharynx and the dental biofilm, and subsequently reduce the aspiration of the contaminated saliva. This possible mechanism was further discussed by Safdar et al. in their review published in $2005 .{ }^{50}$ Also, according to Coker et al., the practice of adequate oral care for these patients promotes holistic patient care, increases their comfort and prevents halitosis. ${ }^{42}$ The maintenance of oral hygiene with constant adequate oral care is also important to prevent the recolonization of the oral cavity by pathogenic microbes. Table 3 summarizes the literature associating bacterial colonization and VAP.

\section{Mechanical dental plaque control}

Dental plaque control for patients on mechanical ventilators is challenging. The main reason is a limited and difficult access to the oral cavity. Evidence also suggests that oral care protocols may not be fully followed by the ICU staff. This is reflected in a survey carried out by Rello et al., ${ }^{28}$ involving 59 European ICUs. In a review regarding the clinical effectiveness of the oral health procedures utilized by nurses, performed by Bowsher et al. in 1999 , it was found that the sponge Toothette ${ }^{\circledR}$ oral swabs frequently used in ICUs showed limited effectiveness in eradicating the dental biofilm as compared to a regular toothbrush. ${ }^{51}$ Therefore, toothbrushes are now thought to be the superior choice in maintaining oral hygiene among ICU patients.

The apparatus for OHC should be carefully chosen based on its benefits, accessibility and potential adverse effects as well as its specific features that set it apart from other 
Table 3. Literature associating bacterial colonization and ventilator-associated pneumonia (VAP)

\begin{tabular}{|c|c|c|}
\hline Articles & Type of literature & Relevant main findings \\
\hline Scannapieco et al. ${ }^{30}$ & $\begin{array}{c}\text { prospective } \\
\text { non-randomized } \\
\text { study }\end{array}$ & $\begin{array}{l}\text { - The oral hygiene of medical ICU patients was poor. } \\
\text { - The dental plaque and/or the oral mucosa of } 65 \% \text { of medical ICU patients were colonized by respiratory } \\
\text { pathogens, in contrast to only } 16 \% \text { of patients in a preventive dentistry clinic (control). } \\
\text { - The potential respiratory pathogens cultured from medical ICU patients included methicillin-resistant } \\
\text { Staphylococcus aureus, Pseudomonas aeruginosa, and } 10 \text { genera of Gram-negative bacilli. }\end{array}$ \\
\hline Garrouste-Orgeas et al. ${ }^{36}$ & prospective study & $\begin{array}{l}\text { - Out of } 86 \text { ventilated ICU patients, } 31 \text { cases of pneumonia were diagnosed ( } 36 \% \text { of patients). } \\
\text { - Oropharyngeal colonization, detected either on admission or from subsequent samples, was } \\
\text { a predominant factor for nosocomial pneumonia in comparison with gastric colonization. } \\
\text { - Oropharyngeal colonization with Acinetobacter baumannii yielded an estimated } 7.45 \text {-fold increased risk } \\
\text { of pneumonia in comparison with patients not yet or not identically colonized ( } p=0.0004) \text {. } \\
\text { - DNA genomic analysis demonstrated that an identical strain was isolated from oropharyngeal, gastric or } \\
\text { bronchial samples in all but } 3 \text { cases of pneumonia due to Staphylococcus aureus. } \\
\text { - The findings provide better knowledge of the pathophysiology of nosocomial pneumonia in } \\
\text { mechanically ventilated patients. }\end{array}$ \\
\hline Safdar et al. ${ }^{50}$ & review & $\begin{array}{l}\text { - VAP is the most common nosocomial infection in ICU, and it is associated with major morbidity and } \\
\text { attributable mortality. } \\
\text { - A major route for acquiring endemic VAP is oropharyngeal colonization by the endogenous flora or } \\
\text { by the pathogens acquired exogenously from the ICU environment, especially the hands or apparel } \\
\text { of healthcare workers, the contaminated respiratory equipment, hospital water, or air. } \\
\text { - The aspiration of the microbe-laden oropharyngeal, tracheal or gastric secretions around the cuffed } \\
\text { endotracheal tube into the normally sterile lower respiratory tract results in most cases of endemic VAP. } \\
\text { - Strategies to eradicate oropharyngeal and/or intestinal microbial colonization, including chlorhexidine } \\
\text { oral care, have been shown (among others) to reduce the risk of VAP. }\end{array}$ \\
\hline
\end{tabular}

oral care equipment; for example, its efficacy in plaque removal. Based on the findings of a randomized trial by Needleman et al., it can be concluded that toothbrushes remain the preferred and standard oral care tool as far as dental plaque removal is concerned, as it is recognized that dental plaque is efficiently cleared by means of mechanical interference. ${ }^{52}$ The findings of a study by Yao et al. published in 2011 indicate that an oral hygiene routine consistently carried out twice daily can significantly reduce the incidence of VAP. ${ }^{53}$ To improve the efficacy of oral hygiene practice, the regularity of care should be determined using daily oral assessments, as suggested by Ames et al. ${ }^{54}$ Conversely, however, a randomized control trial by Lorente et al. found that there was no significant difference in the incidence of VAP in critically ill patients receiving oral care with or without manual toothbrushing. ${ }^{55}$

\section{Electric toothbrush for dental plaque control}

As suggested by Verma and Bhat, powered toothbrushes (PTBs) have been promoted as appliances that offer improved biofilm removal capability when compared to manual toothbrushes. ${ }^{56}$ A Cochrane review by Robinson et al. published in 2009 suggested some advantages of PTBs for plaque removal in comparison with manual toothbrushes. ${ }^{57}$ A systematic review and meta-analysis by Elkerbout et al. regarding single brushing exercises analyzed various studies that compared PTBs with manual toothbrushes to investigate their effectiveness in plaque removal and the outcome was in favor of PTBs. ${ }^{58}$ In clinical settings, PTBs were found to be effective in removing dental plaque, which is supported by a systematic review by Rosema et al. ${ }^{59}$ and a Cochrane review by Yaacob et al. ${ }^{60}$ Powered toothbrushes are also effective in controlling gingivitis. However, research examining the long-term efficacy of PTBs in inhibiting the initiation or progression of periodontitis is limited, as these studies, for instance by Dörfer et al. ${ }^{61}$ and Schmalz et al., ${ }^{62}$ mainly focus on dental plaque, calculus and gingivitis. Needleman et al. concluded that PTBs were exceedingly efficient in removing dental biofilm in intubated ICU patients, and that PTBs should be further evaluated for their potential to reduce the incidence of VAP. ${ }^{52}$ This appliance may also be beneficial in the prevention of lung infections and health complications that are commonly linked to critically ill COVID-19 patients. However, PTBs may not be readily available and their cost may hinder their application as well.

\section{Chemical dental plaque control with chlorhexidine gel}

The fundamental instrument used for the removal of dental biofilm is a manual toothbrush. The action of toothbrushing decreases the oral microbial load, which should significantly reduce the risk of lung infections. Toothbrushing combined with chemical plaque control with $0.12 \%$ chlorhexidine gel reduces the incidence of VAP, shortens the length of the hospital stay and decreases the ICU mortality rate. These findings are supported by a study by Needleman et al..$^{52}$ and a literature review by Zuckerman. ${ }^{63}$ The combined use of a regular toothbrush and $0.12 \%$ chlorhexidine gel has a synergistic effect on dental plaque, which is evident in various stud- 
ies and review papers, including a Cochrane review by Hua et al. published in 2016, which specifically examined OHC for critically ill patients to prevent VAP. ${ }^{64}$ A study by Prendergast et al. emphasized the effectiveness of the combined oral care (which may include the use of a regular toothbrush with chlorhexidine gel) as compared to toothbrushing alone. ${ }^{65}$ It is advocated that the liquids applied for oral care purposes should simultaneously be effective in removing plaque while not causing the irritation of the mucosa or dry mouth. Liquid mixtures that may be used for oral care include chlorhexidine, saline solution and purified water. Studies and review articles by Needleman et al., ${ }^{52}$ Ames et al..$^{54}$ and Zuckerman ${ }^{63}$ revealed that even at a relatively low concentration (between $0.12 \%$ and $0.2 \%$ ), chlorhexidine was still effective in preventing VAP.

The establishment and application of a comprehensive $\mathrm{OHC}$ program is vital for patients who are at high risk of developing VAP in ICU. It is essential to control and remove dental biofilm from tooth surfaces and the oral cavity. A multi-center study by Ames et al. on the effects of systematic oral care in critically ill patients showed that there was a significant improvement of patients' plaque scores along with a reduction of visible plaque depositions in patients when the system was implemented by critical care nurses. ${ }^{54}$ A proper system or program should incor- porate the regular and consistent brushing of the teeth, gingiva and tongue, conducted twice daily (minimum), using a small pediatric or single-tufted toothbrush. This implementation is relevant for ICU patients severely affected by COVID-19 with the aim of reducing morbidity and mortality. Table 4 summarizes various types of literature that discusses the effect of oral health on preventing or reducing VAP.

\section{Conclusions}

It is essential to re-emphasize the importance of adequate oral care for critically ill patients, especially those on mechanical ventilation, to improve their survival. As bacterial infections have been associated with the atypical pneumonia seen in cases of COVID-19, the control of the oral environment and its microbiome seems like a logical step to be taken for these patients. With the combined measures of toothbrushing and chemical plaque control with $0.12 \%$ chlorhexidine gel or other oral care solutions, it is hoped that the incidence of critically ill ventilatordependent COVID-19 patients contracting atypical pneumonia and/or other infections involving distant organs will be greatly reduced.

Table 4. Literature on the effect of oral care on preventing or reducing VAP

\begin{tabular}{|c|c|c|c|}
\hline Oral care & Articles & Type of study & Relevant main findings \\
\hline \multirow[t]{2}{*}{ Chemical only } & Panchabhai et al. ${ }^{25}$ & $\begin{array}{c}\text { randomized } \\
\text { controlled } \\
\text { trial }\end{array}$ & $\begin{array}{l}\text { - } 512 \text { patients admitted to ICU of an Indian tertiary care teaching hospital were randomized } \\
\text { into twice daily oropharyngeal cleansing with } 0.2 \% \text { chlorhexidine (test) or } 0.01 \% \text { potassium } \\
\text { permanganate solution (control). } \\
\text { - Nosocomial pneumonia developed in } 7.1 \% \text { of patients in the chlorhexidine group and } 7.7 \% \text { in } \\
\text { the control group ( } p=0.82 ; R R: 0.93 ; 95 \% \text { Cl: } 0.49-1.76) \\
\text { - During the study period, nosocomial pneumonia developed in fewer subjects ( } 7.4 \%) \text { than in } \\
\text { the } 3 \text { months preceding and following the study }(21.7 \%)(p<0.001) \text {. } \\
\text { - Conclusions: Oropharyngeal cleansing with } 0.2 \% \text { chlorhexidine solution was not superior } \\
\text { to oral cleansing with the control solution; however, a decreased incidence of nosocomial } \\
\text { pneumonia during the study period suggests a possible benefit of meticulous oral hygiene in } \\
\text { ICU patients. }\end{array}$ \\
\hline & Kaya et al. ${ }^{23}$ & $\begin{array}{c}\text { randomized } \\
\text { controlled } \\
\text { trial }\end{array}$ & $\begin{array}{l}\text { - } 88 \text { randomly selected patients from those admitted to neurosurgical ICU were divided into } \\
2 \text { groups: one received oral care with } 5 \% \text { glutamine (test); the other received oral care with } 2 \% \\
\text { chlorhexidine gluconate solution (control). } \\
\text { - There was no statistically significant difference in the mean scores on days 1, } 3 \text { and 5, or upon } \\
\text { discharge }(p>0.05) \text {. } \\
\text { - Conclusions: There was no statistically significant difference between using } 5 \% \text { glutamine or } 2 \% \\
\text { chlorhexidine gluconate solution for oral care for the prevention of VAP. }\end{array}$ \\
\hline Mechanical only & Yao et al. ${ }^{53}$ & $\begin{array}{c}\text { randomized } \\
\text { controlled } \\
\text { trial }\end{array}$ & $\begin{array}{l}\text { - } 53 \text { post-neurosurgical ICU patients were divided into test and control groups. } \\
\text { - Both groups received usual hospital care (i.e., daily oral care using cotton swabs). } \\
\text { - The test group additionally received a twice daily oral care protocol of toothbrushing with } \\
\text { purified water, elevating the head of the bed, and before-and-after hypopharyngeal suctioning. } \\
\text { - The control group received mock oral care twice daily (elevating the head of the bed, } \\
\text { moisturizing the lips, and before-and-after hypopharyngeal suctioning). } \\
\text { - After } 7 \text { days of toothbrushing with purified water, the cumulative VAP rates were statistically } \\
\text { significantly lower in the test group (17\%) than in the control group }(71 \%)(p<0.05) \text {. } \\
\text { - The test group also had statistically significantly better scores for oral health }(p<0.05) \text { and the } \\
\text { plaque index ( } p<0.01) \text {. } \\
\text { - Conclusions: The findings suggest that as an inexpensive alternative to the existing protocols, } \\
\text { toothbrushing twice daily with purified water reduces the risk of VAP, and improves oral health } \\
\text { and hygiene. }\end{array}$ \\
\hline
\end{tabular}




\begin{tabular}{|c|c|c|c|}
\hline Oral care & Articles & Type of study & Relevant main findings \\
\hline \multirow[t]{2}{*}{$\begin{array}{l}\text { Mechanical vs } \\
\text { chemical }\end{array}$} & Needleman et al. ${ }^{52}$ & $\begin{array}{c}\text { randomized } \\
\text { controlled } \\
\text { trial }\end{array}$ & $\begin{array}{l}\text { - Parallel-arm, single-center, examiner- and analyst-masked, randomized controlled trial }(\mathrm{N}=46) \text {. } \\
\text { - Test: PTB; control: sponge Toothette oral swab. } \\
\text { - Both were used } 4 \text { times a day for } 2 \text { min and patients received } 20 \mathrm{~mL} \text { of } 0.2 \% \text { chlorhexidine } \\
\text { mouthwash at each time point. } \\
\text { - The results showed a low prevalence of respiratory pathogens throughout the study period, } \\
\text { with no statistically significant differences between the groups. } \\
\text { - A highly statistically significantly greater reduction in dental plaque was obtained with the use } \\
\text { of PTB in comparison with the control treatment ( } p=0.006) \text {. } \\
\text { - The total viable bacterial count was also highly statistically significantly lower in the test group } \\
\text { at day } 5 \text { ( } p=0.002 \text { ). } \\
\text { - Conclusions: PTBs are highly effective for plaque removal in intubated ICU patients and should } \\
\text { be tested for their potential to reduce the incidence of VAP and health complications. }\end{array}$ \\
\hline & Lorente et al. ${ }^{55}$ & $\begin{array}{l}\text { randomized } \\
\text { clinical trial }\end{array}$ & $\begin{array}{l}\text { - Randomized clinical trial in medical-surgical ICU }(N=436) \text {. } \\
\text { - Test: oral care including } 0.12 \% \text { chlorhexidine digluconate with toothbrushing; control: oral care } \\
\text { including } 0.12 \% \text { chlorhexidine digluconate without toothbrushing. } \\
\text { - There were no statistically significant differences between the groups regarding the incidence } \\
\text { of VAP }(9.7 \% \text {-with toothbrushing vs } 11.0 \% \text { - without toothbrushing) }(p=0.75) \text {. } \\
\text { - Adding manual toothbrushing to chlorhexidine oral care does not help prevent VAP in critically } \\
\text { ill patients on mechanical ventilation. }\end{array}$ \\
\hline $\begin{array}{l}\text { Mechanical and } \\
\text { chemical }\end{array}$ & Berry et al. ${ }^{40}$ & $\begin{array}{c}\text { randomized } \\
\text { comparative } \\
\text { study }\end{array}$ & $\begin{array}{l}\text { - Single-blind, randomized comparative study involving adult ICU patients in a university hospital } \\
\text { ( } N=109) \text {. } \\
\text { - All patients underwent cleaning with a toothbrush and a non-foaming toothpaste. } \\
\text { - Group A (control): additional hourly oral rinse with sterile water; group B (test): additional hourly } \\
\text { sodium bicarbonate mouthwash; group C (test): twice daily irrigations with chlorhexidine } 0.2 \% \\
\text { aqueous oral rinse and additional hourly irrigations with sterile water. } \\
\text { - No significant differences were found between the groups for all clinical data. } \\
\text { - Group B showed a greater trend toward a reduction in bacterial colonization; however, no } \\
\text { significant differences could be demonstrated at day } 4 \text { of admission ( } p=0.302) \text {. } \\
\text { - The incidence of VAP was evenly spread between groups B and C ( } 5 \%) \text {, while in group A, it was } \\
\text { only } 1 \% \text {. } \\
\text { - Conclusions: While a number of studies have advocated the use of various mouth rinses in } \\
\text { reducing the colonization of dental plaque, a standardized oral hygiene protocol that includes } \\
\text { the use of mechanical cleaning with a toothbrush may be a factor reducing the colonization } \\
\text { of dental plaque with respiratory pathogens. }\end{array}$ \\
\hline \multirow{3}{*}{$\begin{array}{l}\text { Mechanical } \\
\text { and/or } \\
\text { chemical }\end{array}$} & Hillier et al. ${ }^{27}$ & review & $\begin{array}{l}\text { - No consensus on best practice for oral hygiene in patients being treated with mechanical } \\
\text { ventilation has been found. } \\
\text { - Although chlorhexidine is the most popular oral care product, no consensus has emerged on } \\
\text { its concentration or protocols for oral care. } \\
\text { - The implementation of an oral care protocol, ongoing nurse education and evaluation are } \\
\text { important in reducing the incidence of VAP. }\end{array}$ \\
\hline & Zuckerman $^{63}$ & review & $\begin{array}{l}\text { - Oral health has been shown to greatly contribute to the development or prevention of VAP; it } \\
\text { can be compromised by critical illness and mechanical ventilation while being influenced by } \\
\text { nursing care. } \\
\text { - Oral health is managed by proper oral care with the use of oral chlorhexidine in order to } \\
\text { decrease oral bacteria and the potential oropharynx colonization. } \\
\text { - There is a decrease in the VAP rates with the use of oral interventions, such as chlorhexidine. } \\
\text { - The research results support and influence patient care practices, considering that nursing and } \\
\text { medicine are driven by evidence rather than experience to prevent avoidable patient harm. }\end{array}$ \\
\hline & Hua et al. ${ }^{64}$ & review & $\begin{array}{l}\text { - OHC, including chlorhexidine mouthwash or gel, reduces the risk of developing VAP in } \\
\text { critically ill patients from } 24 \% \text { to about } 18 \% \text {; however, there is no evidence of a difference in } \\
\text { the outcomes with regard to mortality, the duration of mechanical ventilation or the duration } \\
\text { of the ICU stay. } \\
\text { - There is no evidence that OHC including both antiseptics and toothbrushing is different from } \\
\text { OHC with antiseptics alone. } \\
\text { - Some weak evidence suggests that povidone iodine mouth rinse is more effective than saline/ } \\
\text { placebo, and saline rinse is more effective than saline swab in reducing VAP. } \\
\text { - There is no sufficient evidence to determine whether PTBs or other oral care solutions are } \\
\text { effective in reducing VAP. } \\
\text { - There is also insufficient evidence to determine whether any of the interventions evaluated in } \\
\text { the studies are associated with adverse effects. }\end{array}$ \\
\hline
\end{tabular}

$R R$ - relative risk; $\mathrm{Cl}$ - confidence interval; PTB - powered toothbrush; $\mathrm{OHC}$ - oral hygiene care. 


\section{ORCID iDs}

Fouad Hussain Al-Bayaty (1) https://orcid.org/0000-0002-3117-595X Najwa Baharudin (1) https://orcid.org/0000-0002-8579-8001 Mohamed Ibrahim Abu Hassan (1) https://orcid.org/0000-0002-8724-6702

\section{References}

1. Socransky SS, Haffajee AD, Cugini MA, Smith C, Kent RL Jr. Microbial complexes in subgingival plaque. J Clin Periodontol. 1998;25(2):134-144. doi:10.1111/j.1600-051x.1998.tb02419.x

2. Larjava $H$, Koivisto $L$, Häkkinen $L$, Heino J. Epithelial integrins with special reference to oral epithelia. J Dent Res. 2011;90(12):1367-1376. doi:10.1177/0022034511402207

3. Public Health Ontario. COVID-19 in Ontario: January 15,2020 to July 22, 2020. https://files.ontario.ca/moh-covid-19-report-en-2020-07-23.pdf. Accessed August 3, 2020.

4. Ruan $Q$, Yang K, Wang W, Jiang L, Song J. Clinical predictors of mortality due to COVID-19 based on an analysis of data of 150 patients from Wuhan, China. Intensive Care Med. 2020;46(5):846-848. doi:10.1007/s00134-020-05991-x

5. Vincent $J$, Taccone FS. Understanding pathways to death in patients with COVID-19. Lancet Respir Med. 2020;8(5):430-432. doi:10.1016/S2213-2600(20)30165-X

6. World Health Organization. WHO Coronavirus (COVID-19) Dashboard. https://covid19.who.int/. Accessed September 30, 2020.

7. Chen N, Zhou M, Dong X, et al. Epidemiological and clinical characteristics of 99 cases of 2019 novel coronavirus pneumonia in Wuhan, China: A descriptive study. Lancet. 2020;395(10223):507-513. doi:10.1016/S0140-6736(20)30211-7

8. Wang D, Hu B, Hu C, et al. Clinical characteristics of 138 hospitalized patients with 2019 novel coronavirus-infected pneumonia in Wuhan, China. JAMA. 2020;323(11):1061-1069. doi:10.1001/jama.2020.1585

9. Xie J, Tong Z, Guan X, Du B, Qiu H, Slutsky AS. Critical care crisis and some recommendations during the COVID-19 epidemic in China. Intensive Care Med. 2020;46(5):837-840. doi:10.1007/s00134-020-05979-7

10. Huang $C$, Wang $Y, L i X$, et al. Clinical features of patients infected with 2019 novel coronavirus in Wuhan, China. Lancet. 2020;395(10223):497-506. doi:10.1016/S0140-6736(20)30183-5

11. Liu K, Fang YY, Deng Y, et al. Clinical characteristics of novel coronavirus cases in tertiary hospitals in Hubei province. Chin Med J (Engl). 2020;133(9):1025-1031. doi:10.1097/CM9.0000000000000744

12. Ragab D, Eldin HS, Taeimah M, Khattab R, Salem R. The COVID-19 cytokine storm; what we know so far. Front Immunol. 2020;11:1446. doi:10.3389/fimmu.2020.01446

13. Shimizu M. Clinical features of cytokine storm syndrome. In: Cron R, Behrens EM, eds. Cytokine Storm Syndrome. Cham, Switzerland: Springer International Publishing; 2019:31-41. doi:10.1007/978-3-030-22094-5_3

14. Coperchini F, Chiovato L, Croce L, Magri F, Rotondi M. The cytokine storm in COVID-19: An overview of the involvement of the chemokine/chemokine-receptor system. Cytokine Growth Factor Rev. 2020;53:25-32. doi:10.1016/j.cytogfr.2020.05.003

15. Bhatia $M$, Zemans $R L$, Jeyaseelan $S$. Role of chemokines in the pathogenesis of acute lung injury. Am J Respir Cell Mol Biol. 2012;46(5):566-572. doi:10.1165/rcmb.2011-0392TR

16. Lai CC, Shih TP, Ko WC, Tang HJ, Hsueh PR. Severe acute respiratory syndrome coronavirus 2 (SARS-CoV-2) and coronavirus disease-2019 (COVID-19): The epidemic and the challenges. Int J Antimicrob Agents. 2020;55(3):105924. doi:10.1016/j.jjantimicag.2020.105924

17. Guan W, Ni Z, Hu Y, et al. Clinical characteristics of coronavirus disease 2019 in China. N Engl J Med. 2020;382(18):1708-1720. doi:10.1056/NEJMoa2002032

18. Tang Y, Liu J, Zhang D, Xu Z, Ji J, Wen C. Cytokine storm in COVID-19: The current evidence and treatment strategies. Front Immunol. 2020;11:1708. doi:10.3389/fimmu.2020.01708

19. Cao X. COVID-19: Immunopathology and its implications for therapy. Nat Rev Immunol. 2020;20(5):269-270. doi:10.1038/s41577-020-0308-3

20. Wang $\mathrm{H}, \mathrm{Ma} \mathrm{S}$. The cytokine storm and factors determining the sequence and severity of organ dysfunction in multiple organ dysfunction syndrome. Am J Emerg Med. 2008;26(6):711-715. doi:10.1016/j.ajem.2007.10.031
21. Yang $Y, L u$ QB, Liu MJ, et al. Epidemiological and clinical features of the 2019 novel coronavirus outbreak in China. medRxiv. 2020. doi:10.1101/2020.02.10.20021675

22. Adib-Hajbaghery M, Ansari A, Azizi-Fini I. Intensive care nurses' opinions and practice for oral care of mechanically ventilated patients. Indian J Crit Care Med. 2013;17(1):23-27. doi:10.4103/0972-5229.112154

23. Kaya $H$, Turan $Y$, Tunalı $Y$, et al. Effects of oral care with glutamine in preventing ventilator-associated pneumonia in neurosurgical intensive care unit patients. Appl Nurs Res. 2017;33:10-14. doi:10.1016/j.apnr.2016.10.006

24. Fields LB. Oral care intervention to reduce incidence of ventilatorassociated pneumonia in the neurologic intensive care unit. J Neurosci Nurs. 2008:40(5):291-298. doi:10.1097/01376517-200810000-00007

25. Panchabhai TS, Dangayach NS, Krishnan A, Kothari VM, Karnad DR. Oropharyngeal cleansing with $0.2 \%$ chlorhexidine for prevention of nosocomial pneumonia in critically ill patients: An open-label randomized trial with $0.01 \%$ potassium permanganate as control. Chest. 2009;135(5):1150-1156. doi:10.1378/chest.08-1321

26. Pedreira MLG, Kusahara DM, Brunow de Carvalho W, Núñez SC, Peterlini MAS. Oral care interventions and oropharyngeal colonization in children receiving mechanical ventilation. Am J Crit Care. 2009;18(4):319-329. doi:10.4037/ajcc2009121

27. Hillier B, Wilson C, Chamberlain D, King L. Preventing ventilatorassociated pneumonia through oral care, product selection, and application method: A literature review. AACN Adv Crit Care. 2013;24(1):38-58. doi:10.1097/NCI.0b013e31827df8ad

28. Rello J, Koulenti D, Blot S, et al. Oral care practices in intensive care units: A survey of 59 European ICUs. Intensive Care Med. 2007;33(6):1066-1070. doi:10.1007/s00134-007-0605-3

29. Scannapieco FA, Stewart EM, Mylotte JM. Colonization of dental plaque by respiratory pathogens in medical intensive care patients. Crit Care Med. 1992;20(6):740-745. doi:10.1097/00003246-199206000-00007

30. Haghighi A, Shafipour V, Bagheri-Nesami M, Baradari AG, Charati JY. The impact of oral care on oral health status and prevention of ventilator-associated pneumonia in critically ill patients. Aust Crit Care. 2017;30(2):69-73. doi:10.1016/j.aucc.2016.07.002

31. GBD 2016 Disease and Injury Incidence and Prevalence Collaborators. Global, regional, and national incidence, prevalence, and years lived with disability for 328 diseases and injuries for 195 countries, 1990-2016: A systematic analysis for the Global Burden of Disease Study 2016. Lancet. 2017;390(10100):1211-1259. doi:10.1016/S0140-6736(17)32154-2

32. Kim J, Amar S. Periodontal disease and systemic conditions: A bidirectional relationship. Odontology. 2006;94(1):10-21. doi:10.1007/s10266-006-0060-6

33. Paster BJ, Boches SK, Galvin JL, et al. Bacterial diversity in human subgingival plaque. J Bacteriol. 2001;183(12):3770-3783. doi:10.1128/JB.183.12.3770-3783.2001

34. Liu B, Faller LL, Klitgord N, et al. Deep sequencing of the oral microbiome reveals signatures of periodontal disease. PLoS One. 2012;7(6):e37919. doi:10.1371/journal.pone.0037919

35. Gomes-Filho IS, Passos JS, Seixas da Cruz S. Respiratory disease and the role of oral bacteria. J Oral Microbiol. 2010;2. doi:10.3402/jom.v2i0.5811

36. Garrouste-Orgeas M, Chevret S, Arlet G, et al. Oropharyngeal or gastric colonization and nosocomial pneumonia in adult intensive care unit patients. A prospective study based on genomic DNA analysis. Am J Respir Crit Care Med. 1997;156(5):1647-1655. doi:10.1164/ajrccm.156.5.96-04076

37. Munro CL, Grap MJ. Oral health and care in the intensive care unit: State of the science. Am J Crit Care. 2004;13(1):25-34. doi:10.4037/ajcc2004.13.1.25

38. El-Solh AA, Pietrantoni $C$, Bhat $A$, et al. Colonization of dental plaques: A reservoir of respiratory pathogens for hospital-acquired pneumonia in institutionalized elders. Chest. 2004;126(5):1575-1582. doi:10.1378/chest.126.5.1575

39. Weidlich P, Cimões R, Pannuti CM, Oppermann RV. Association between periodontal diseases and systemic diseases. Braz Oral Res. 2008;22(Suppl 1):32-43. doi:10.1590/s1806-83242008000500006

40. Berry AM, Davidson PM, Masters J, Rolls K, Ollerton R. Effects of three approaches to standardized oral hygiene to reduce bacterial colonization and ventilator associated pneumonia in mechanically ventilated patients: A randomised control trial. Int J Nurs Stud. 2011;48(6):681-688. doi:10.1016/j.ijnurstu.2010.11.004 
41. Genco RJ, Borgnakke WS. Risk factors for periodontal disease. Periodontol 2000.2013;62(1):59-94. doi:10.1111/j.1600-0757.2012.00457.x

42. Coker E, Ploeg J, Kaasalainen S, Fisher A. A concept analysis of oral hygiene care in dependent older adults. $J$ Adv Nurs. 2013:69(10):2360-2371. doi:10.1111/jan.12107

43. Yurdanur D, Yagmur FN. A recent view and evidence-based approach to oral care of intensive care patient. Int J Caring Sci. 2016;9:1177-1185. http://internationaljournalofcaringsciences.org/ docs/50 yurdanur_review_9 3.pdf. Accessed August 3, 2020.

44. Berry AM, Davidson PM, Masters J, Rolls K. Systematic literature review of oral hygiene practices for intensive care patients receiving mechanical ventilation. Am J Crit Care. 2007;16(6):552-563. doi:10.4037/ajcc2007.16.6.552

45. Cirillo F, Hinkelbein J, Romano GM, Piazza O, Servillo G, De Robertis E. Ventilator associated pneumonia and tracheostomy. Trends Anaesth Crit Care. 2015;5(6):184-188. doi:10.1016/j.tacc.2015.10.003

46. Inchai J, Pothirat C, Bumroongkit C, Limsukon A, Khositsakulchai W, Liwsrisakun C. Prognostic factors associated with mortality of drugresistant Acinetobacter baumannii ventilator-associated pneumonia. J Intensive Care. 2015;3:9. doi:10.1186/s40560-015-0077-4

47. DeKeyser Ganz F, Ofra R, Khalaila R, et al. Translation of oral care practice guidelines into clinical practice by intensive care unit nurses. J Nurs Scholarsh. 2013;45(4):355-362. doi:10.1111/jnu.12039

48. Atay S, Karabacak Ü. Oral care in patients on mechanical ventilation in intensive care unit: Literature review. Int J Res Med Sci. 2014;2(3):822-829. doi:10.5455/2320-6012.ijrms20140876

49. Feider LL, Mitchell $P$, Bridges E. Oral care practices for orally intubated critically ill adults. Am J Crit Care. 2010;19(2):175-183. doi:10.4037/ajcc2010816

50. Safdar N, Crnich CJ, Maki DG. The pathogenesis of ventilatorassociated pneumonia: Its relevance to developing effective strategies for prevention. Respir Care. 2005;50(6):725-741.

51. Bowsher J, Boyle S, Griffiths J. Oral care. Nurs Stand. 1999;13(37):31. doi:10.7748/ns.13.37.31.s50

52. Needleman IG, Hirsch NP, Leemans M, et al. Randomized controlled trial of toothbrushing to reduce ventilator-associated pneumonia pathogens and dental plaque in a critical care unit. JClin Periodontol. 2011;38(3):246-252. doi:10.1111/j.1600-051X.2010.01688.x

53. Yao LY, Chang CK, Maa SH, Wang C, Chen CCH. Brushing teeth with purified water to reduce ventilator-associated pneumonia. J Nurs Res. 2011;19(4):289-297. doi:10.1097/JNR.0b013e318236d05f

54. Ames NJ, Sulima P, Yates JM, et al. Effects of systematic oral care in critically ill patients: A multicenter study. Am J Crit Care. 2011;20(5):e103-e114. doi:10.4037/ajcc2011359

55. Lorente $L$, Lecuona $M$, Jiménez $A$, et al. Ventilator-associated pneumonia with or without toothbrushing: A randomized controlled trial. Eur J Clin Microbiol Infect Dis. 2012;31(10):2621-2629. doi:10.1007/s10096-012-1605-y

56. Verma S, Bhat KM. Acceptability of powered toothbrushes for elderly individuals. J Public Health Dent. 2004;64(2):115-117. doi:10.1111/j.1752-7325.2004.tb02738.x

57. Robinson PG, Deacon SA, Deery $C$, et al. Manual versus powered toothbrushing for oral health. Cochrane Database Syst Rev. 2005;2005(2):CD002281. doi:10.1002/14651858.CD002281.pub2

58. Elkerbout TA, Slot DE, Martijn Rosema NA, Van der Weijden GA. How effective is a powered toothbrush as compared to a manual toothbrush? A systematic review and meta-analysis of single brushing exercises. Int J Dent Hyg. 2020;18(1):17-26. doi:10.1111/idh.12401

59. Rosema N, Slot DE, van Palenstein Helderman WH, Wiggelinkhuizen $L$, Van der Weijden GA. The efficacy of powered toothbrushes following a brushing exercise: A systematic review. Int J Dent Hyg. 2016;14(1):29-41. doi:10.1111/idh.12115

60. Yaacob M, Worthington HV, Deacon SA, et al. Powered versus manual toothbrushing for oral health. Cochrane Database Syst Rev. 2014;2014(6):CD002281. doi:10.1002/14651858.CD002281.pub3

61. Dörfer CE, Staehle HJ, Wolff D. Three-year randomized study of manual and power toothbrush effects on pre-existing gingival recession. J Clin Periodontol. 2016;43(6):512-519. doi:10.1111/jcpe.12518

62. Schmalz G, Möller M, Schmickler J, et al. Influence of manual and power toothbrushes on clinical and microbiological findings in initial treatment of periodontitis - a randomized clinical study. Am J Dent. 2017;30(1):40-46.
63. Zuckerman LM. Oral chlorhexidine use to prevent ventilator-associated pneumonia in adults: Review of the current literature. Dimens Crit Care Nurs. 2016;35(1):25-36. doi:10.1097/DCC.0000000000000154

64. Hua F, Xie H, Worthington HV, Furness S, Zhang Q, Li C. Oral hygiene care for critically ill patients to prevent ventilator-associated pneumonia. Cochrane Database Syst Rev. 2016;2016(10):CD008367. doi:10.1002/14651858.CD008367.pub3

65. Prendergast $V$, Jakobsson $U$, Renvert $S$, Hallberg IR. Effects of a standard versus comprehensive oral care protocol among intubated neuroscience ICU patients: Results of a randomized controlled trial. JNeurosciNurs. 2012;44(3):134-148. doi:10.1097/JNN.0b013e3182510688 